\title{
Comparison of floral traits in Calibrachoa cultivars and assessment of their impacts on attractiveness to flower-visiting insects
}

\author{
Melanie Marquardt ${ }^{1}$ (D) Lydia Kienbaum ${ }^{2} \cdot$ Dominik Losert $^{2} \cdot$ Lea Annina Kretschmer ${ }^{1} \cdot$ Marina Rigling $^{3}$. \\ Yanyan Zhang ${ }^{3} \cdot$ Karsten Schweikert $^{4} \cdot$ Nils Westermann $^{5} \cdot$ Ute Ruttensperger $^{5} \cdot$ Peter Rosenkranz $^{1}$
}

Received: 23 December 2020 / Accepted: 1 June 2021 / Published online: 29 June 2021

(c) The Author(s) 2021

\begin{abstract}
Ornamental plants are appreciated by humans for their colorfulness, beauty, abundant flowering and long blooming periods. Many ornamental plants can also constitute an additional foraging resource for flower-visiting insects. However, the ability of the popular ornamental plant Calibrachoa to support urban insect communities is not well documented. In this study, 20 different Calibrachoa cultivars were selected and tested in regard to their insect friendliness based on standardized observations (I) in flight tents using the large earth bumble bee Bombus terrestris as a model species and (II) in open field trials. To investigate what floral characteristics might constitute attractiveness to bumble bees, various floral traits were recorded and compared across all tested Calibrachoa cultivars. Over a two-year period, a total of 6,327 foraging bumble bees were recorded in the tent observations. In the open field observations, we counted 4,188 flower-visiting insects. Our results revealed that (I) all Calibrachoa cultivars were visited by insects for foraging, (II) the number of insect visitors varied significantly among the 20 tested cultivars and (III) the cultivars displayed different floral traits. For the morphometric floral traits and the aroma profiles of Calibrachoa, only the mean nectar quantity and a few identified compounds could be correlated with attractiveness to the model species $B$. terrestris. We also found that the petal color of the tested cultivars had a significant impact on the number of visitors. Therefore, B. terrestris clearly preferred red or blue Calibrachoa cultivars over those with other petal colors. However, as the cultivar preferences in the different insect groups differed, it is highly recommended to use various cultivars in urban plantings. Nevertheless, efforts must be made to explain what additional floral traits make Calibrachoa and other ornamental plants generally attractive to flower visitors. This information can then be used for breeding purposes to increase the insect friendliness of ornamental plants.
\end{abstract}

Keywords Ornamental plant $\cdot$ Calibrachoa cultivars $\cdot$ Floral traits $\cdot$ Flower-visiting insects attractiveness

\section{Introduction}

Handling Editor: Isabel Alves dos Santos.

Melanie Marquardt

melanie.marquardt@uni-hohenheim.de

1 Apicultural State Institute, University of Hohenheim, Erna-Hruschka-Weg 6, 70599 Stuttgart, Germany

2 Selecta One (Klemm \& Sohn GmbH \& Co. KG), Hanfäcker 10, 70378 Stuttgart, Germany

3 Department of Flavor Chemistry, University of Hohenheim, Fruwirthstr. 12, 70599 Stuttgart, Germany

4 Core Facility Hohenheim and Institute of Economics, University of Hohenheim, Schloss Hohenheim 1C, 70599 Stuttgart, Germany

5 State Horticultural College and Research Institute Heidelberg, Diebsweg 2, 69126 Heidelberg, Germany
Urbanization, the expansion of urban and suburban areas, is increasing worldwide (United Nations 2014), resulting in a drastic and permanent change in landscape utilization (Seto et al. 2013). As a consequence, the deterioration of the quantity and quality of natural and seminatural habitats is increased, which dramatically challenges wildlife (McIntyre et al. 2001; McKinney 2006; Winfree et al. 2009; Potts et al. 2010; Ushimaru et al. 2014). Nevertheless, some recently published studies concluded that cities could constitute a valuable habitat, or a retreat, for many insect species (Bates et al. 2011; Hall et al. 2017; Baldock et al. 2019; Theodorou et al. 2020), and scientists repeatedly argued that to support local insect diversity, green urban areas can play a crucial role (Matteson et al. 2008; Gunnarsson and Federsel 2014; 
Hülsmann et al. 2015; Banaszak-Cibicka et al. 2018; Egerer et al. 2020; Wenzel et al. 2020).

Green urban areas such as parks, community gardens, cemeteries and public or private yards belong to the most anthropogenically altered and managed landscapes, providing extensive areas that frequently contain large numbers of flowering plant species. In contrast to natural habitats, urban plant species diversity is generally increased because exotic plants are willingly introduced and planted in addition to naturally occurring plants (Hope et al. 2003; Knapp et al. 2012). Previous studies demonstrated that exotic plants could constitute a useful floral resource for many bee species when they provide nectar and/or pollen (Comba et al. 1999; Corbet et al. 2001). Furthermore, some other studies showed that exotic plants can be equally attractive to flower visitors as native plants (Harrison and Winfree 2015; Lowenstein et al. 2019), and a recently published study indicated that exotic plants might even be a substitute for some native plants when they become scarce (Staab et al. 2020). However, the attractiveness of exotic plants seems to be dependent on the variety itself, and in some cases, different varieties of one species might show enormous differences in their attractiveness to insect flower visitors (Garbuzov and Ratnieks 2015; Erickson et al. 2020).

Generalist flower visitors such as honey bees and bumble bees must choose from a wide range of flowering plants, and they are constantly faced with the decision of what flower(s) to visit for foraging (Chittka and Raine 2006). Many flowering plant species, on the other hand, are dependent on insect pollination, and to attract pollinators, these flowers usually display various so-called floral signals. Generally, floral signals consist of visual cues, e.g., flower color and flower shape, as well as olfactory cues (flower scent) (Raguso 2004). In combination, floral signals constitute a complex interplay and form a combined stimulus in bees (Rowe and Guilford 1999), leading to the decision of whether a specific flower is visited or not. Although the importance of flower morphology and flower scent in native flowering plants to bumble bees has been intensively discussed in many previous publications (e.g.Harder 1983; Kunze and Gumbert 2001; Ishii 2006; Kulahci et al. 2008), it is still unclear what floral signals drive pollinator choice in exotic or ornamental plants, and so far, no study has investigated the importance of floral signals in these plants on pollinator attractiveness.

As public awareness of the current biodiversity loss, especially in insects, rises, the demand for insect-friendly garden plants increases simultaneously. Many lists recommending 'bee- and butterfly friendly' plants have been published so far, but these recommendations are often based on personal opinions rather than on scientific data (Garbuzov and Ratnieks 2014a). This is especially true for ornamental plants. Additionally, the high number of plant breeding programs that continuously lead to the creation of new and innovated cultivars with enhanced plant characteristics (De 2017) but mostly unknown degrees of insect friendliness aggravates this situation. One particularly relevant example is Calibrachoa Cerv., also known as Calibrachoa Lave \& Lex., a fairly new but very popular ornamental plant with increasing economic importance (Rode et al. 2010; Jędrzejuk et al. 2017). The genus Calibrachoa Cerv. is native to Southern America, mainly Brazil, and the 27 associated species of this genus are all known to be self-incompatible and therefore highly dependent on insect pollination (Stehmann and Semir 1997; Olmstead et al. 2008; Fregonezi et al. 2012, 2013). The ornamental plant Calibrachoa hybrida was first introduced to the Japanese market in approximately 1990, followed by markets in Europe and North America (Murakami et al. 2004). However, these cultivars originated from the hybridization of various unknown wild Calibrachoa Cerv. species; therefore, the actual species origin of these cultivars remains unclear (Kishimoto et al. 2019; Liu et al. 2020). At present, the ornamental plant Calibrachoa hybrida is appreciated by gardeners for its high abundance of flowers and long blooming period, which lasts from approximately May to November in Central Europe. Additionally, garden centers and nurseries offer a wide variety of cultivars in a large range of appealing flower colors, which makes Calibrachoa hybrida a long-flowering, colorful and attractive bedding and balcony plant (Murakami et al. 2004). However, knowledge of Calibrachoa hybrida in regard to its insect friendliness is scarce, and to date, no study has investigated whether, and to what extent, differences in attractiveness exist among cultivars of Calibrachoa hybrida.

In this study, we present data on the attractiveness of 20 cultivars of the ornamental garden plant Calibrachoa hybrida to flower-visiting insects. The floral visitation patterns of the insects were monitored at two testing sites in southern Germany over a 3-year period (2017-2019), and therefore, two different approaches were devised: (I) tests under controlled, seminatural conditions in flight tents using Bombus terrestris as a model species and (II) field trials analyzing the whole spectrum of insects foraging at our tested plants. With this setup, we tried to assess whether and to what extent the attractiveness differed within the tested cultivars. As a further objective of our study, we compared some floral traits of these cultivars, e.g., flower size, flower color and flower scent, that are assumed to attract flowervisiting insects. The aim was to identify floral traits that can be directly linked with insect friendliness in our Calibrachoa cultivars. 


\section{Materials \& methods}

\section{Tested plant cultivars}

Ornamental plants from the genus Calibrachoa Lave \& Lex. (Wijsman 1990), hereafter referred to as the common name 'Calibrachoa', were tested in this study. We chose these plants, as they (I) are available in a wide range of different petal colors, (II) have a long blooming period and (III) are commonly visited by insects for foraging. In Germany, Calibrachoa is known to be a nonnative (exotic) garden plant that grows annually. For this study, single flower Calibrachoa cultivars in five different petal color sets were selected: 'red', 'white', 'yellow', 'blue' and 'rave', which has radially symmetric patterns. Each color set consisted of four different genotypes, resulting in a total of 20 different Calibrachoa cultivars that were tested in this study. In Germany, these cultivars are currently widely available on sale and marketed in five series: MiniFamous ${ }^{\circledR}$ Neo, MiniFamous ${ }^{\circledR}$ Uno, MiniFamous ${ }^{\circledR}$ Piú, MiniFamous ${ }^{\circledR}$ and Rave ${ }^{\circledR}$ (Table 1).

In all three study years, the 20 Calibrachoa cultivars were supplied as cuttings by the plant breeding company Selecta One (Klemm \& Sohn GmbH \& Co. KG, Stuttgart, Germany, link to the company's website: https://www.selecta-one.com/ en/home/), where they were derived from proprietary breeding lines. The subsequent cultivation of the cuttings was performed in a greenhouse at the State Horticultural College and Research Institute Heidelberg (Heidelberg, Germany). In mid-May, after cultivation, the plants were either planted outdoors in Heidelberg or transported to the State School for Horticulture in Stuttgart-Hohenheim (Stuttgart, Germany), where they were also planted outdoors.

\section{Experimental setup, observations and hand net catching}

This study was performed on the premises of the State Horticultural College and Research Institute Heidelberg (Heidelberg) and the State School for Horticulture in Stuttgart-Hohenheim (Stuttgart). The testing site in Heidelberg is located in a suburban area with a high degree of adjacent agricultural land with the following coordinates: $49^{\circ} 24^{\prime} 10.1^{\prime \prime N} 8^{\circ} 39^{\prime} 03.4^{\prime \prime} \mathrm{E}$. The testing site in Stuttgart is also located in a suburban area that is surrounded by mainly agricultural land. However, this location is situated inside a landscape conservation area, and the coordinates are as follows: $48^{\circ} 42^{\prime} 44.9^{\prime \prime} \mathrm{N} 9^{\circ} 11^{\prime} 56.6^{\prime \prime} \mathrm{E}$. At both locations, three flight tents with the dimensions $4 \mathrm{~m} \times 9 \mathrm{~m} \times 3 \mathrm{~m}$ (width $\mathrm{x}$ length $\mathrm{x}$ height) were established and lined with landscape fabric (Mypex). Each flight tent was equipped with the 20 plant cultivars of Calibrachoa, which were planted in $30 \mathrm{~L}$ pots filled with soil (Einheitserde Primel \& Viola (Patzer), medium texture with $2 \mathrm{~kg}$ Osmocote 5-6 $\mathrm{M}$ and $1 \mathrm{~kg}$ start fertilizer + iron chelate). Three individual plants of one cultivar were planted in one pot, and the 20 pots were arranged randomly within the flight tents. Automatic drip irrigation was connected to each pot to ensure adequate irrigation. When required, slug pellets (Bayer Mollustop ${ }^{\circledR}$ ) and green lacewing larvae (Katz Biotech, Chrysoperla carnea) were applied to kill pests.

To determine the attractiveness of the 20 Calibrachoa cultivars to flower visitors, we performed two tests:

(I) Observations of bumble bee colonies in flight tents Observations of the large earth bumble bee (Bombus terrestris) took place at both testing sites in Heidelberg and Stuttgart in 2017 and 2018. For this purpose, bumble bee colonies (Katz Biotech, Bombus terrestris mini colony or Sauter \& Stepper, NATUPOL standard bumble bee colony Bombus terrestris) were purchased, and each flight tent was equipped with two bumble bee colonies. Each Calibrachoa cultivar was observed for $2 \mathrm{~min}$, and the number of flower-visiting bumble bees was recorded. We only counted the visits when workers came in contact with the reproductive parts of the flowers and/or when they were observed actively foraging on the floral products of our plant cultivars. All 20 cultivars in the three flight tents were tested this way, and the observations were repeated three times per day. The observations were conducted only on days with favorable weather, i.e., on days with a minimum peak daytime temperature of $20{ }^{\circ} \mathrm{C}$, low wind and full to partial sun. In Stuttgart, in 2017, there were 13 observation days, and in 2018, there were 12 observation days. In Heidelberg, in 2017, there were 15 observation days, and in 2018 , there were 20 observation days. Observations took place between 07:00 am and 03:00 pm.

(II) Open field

Observations of the open field test without gauze were conducted only in Stuttgart in 2017 and 2019. Again, the number of flower visitors that were foraging on pollen or nectar from Calibrachoa was recorded, but this time, we used the 'snap-shot' method to acquire the data. In this method, the plants were observed just briefly, with a maximal duration of a couple seconds. In this short period of time, the number of foraging insects was recorded. The recorded insects were broadly identified in the field and then classified into the following five groups: honey bees (Apis mellifera L.), bumble bees (Bombus spp.), other wild bees (non-Apis and non-Bombus), hoverflies (Diptera: Syrphidae) and other pollinating insects (flies, wasps, beetles, but- 

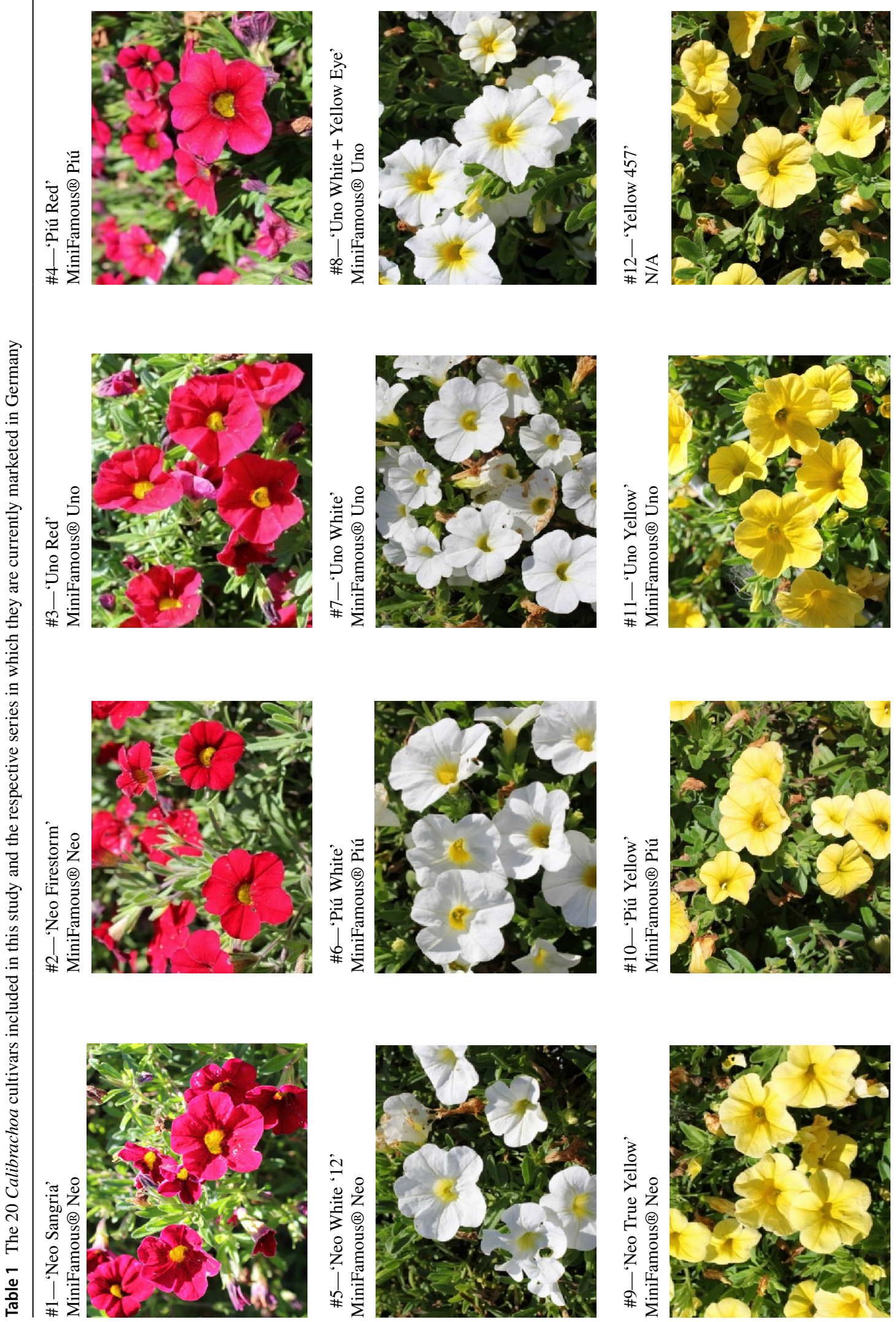

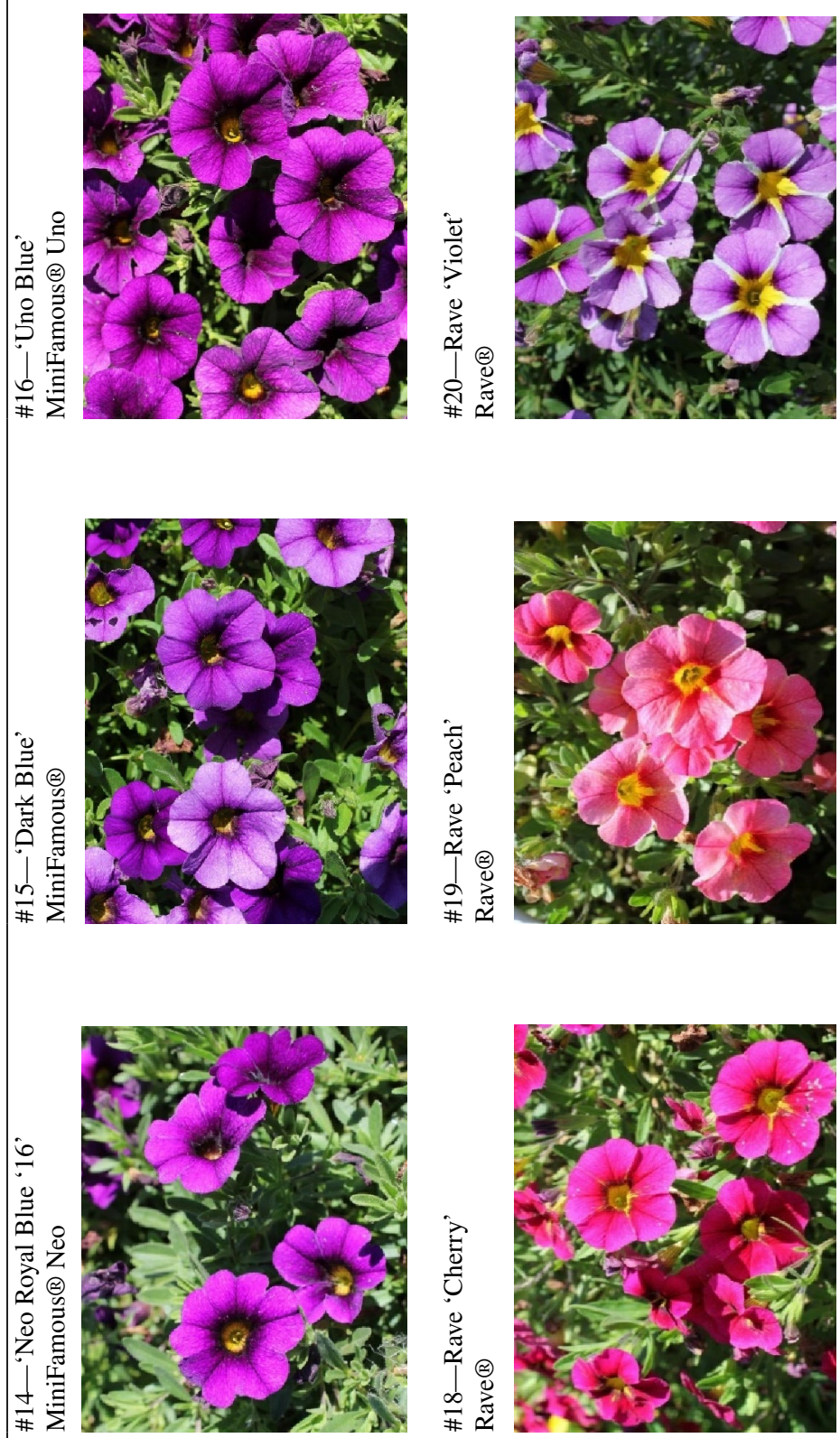

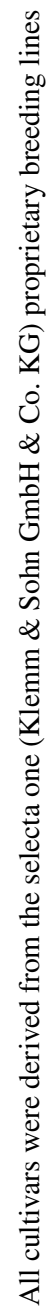


terflies and moths). All 20 cultivars in the three 'flight tents' were observed in this way, and the observations were again repeated three times per day. The observations were also performed only under favorable weather conditions and took place between 09:30 am and 04:45 pm. In 2017, there were 11 observation days, and in 2019 , there were 9 observation days.

Additionally, foraging bumble bees and other wild bees were caught with a hand net (Bioform hand net, diameter $50 \mathrm{~cm}$, mesh size $1 \mathrm{~mm}$, Nürnberg, Germany) in three catching rounds on the mornings of July 10th, August 2nd and August 23rd in 2019. Within two-minute periods, all nectar or pollen foraging bumble bees and other wild bees on Calibrachoa were caught and killed with ethyl acetate. The captured bees were stored in the freezer until the final preparation and determination of the species.

\section{Petal color analyses}

The spectral reflectance of the petals of all 20 Calibrachoa cultivars was recorded from 300 to $700 \mathrm{~nm}$ with an Ocean Optics Jaz Spectrometer (Ocean Optics Inc., Dunedin, FL, USA). The light source was an Ocean Optics deuterium-halogen lamp that shone light over a fiber reflection probe (QR-400-7-UV-VIS, core diameter $400 \mu \mathrm{m}$, length $400 \mathrm{~mm}$ ). The light reached the petal surface at an angle of $45^{\circ}$. A Zeiss MS 20 white ceramic plate and an open black film canister were used as black and white standards. For the measurements, only the flowering plants from the testing site in Stuttgart were used. Five flowers of each cultivar from all three tents were randomly picked and measured. All measurements were performed in 2019, except for the cultivar 'Yellow 457', as its spectral reflectance was already recorded in 2017.

\section{Floral morphometric measurements}

At both testing sites in Heidelberg and Stuttgart in 2017, the flower diameters (horizontally and vertically) and corolla diameters (horizontally and vertically) of 30 randomly picked flowers in all tested cultivars were measured with the help of a custom ruler, and the corolla depths of these flowers were further assessed with a tire tread gauge. In addition, at the testing site in Heidelberg, the lengths of the five stamens in 30 flowers per cultivar were recorded. For this measurement, the flowers were carefully cut in half with a sharp knife, and the lengths of the five stamens were measured with a ruler (Supplementary Information Fig. S1). To determine the nectar quantity per cultivar, we collected nectar samples at the testing site in Stuttgart in 2018. The samples (30 flowers randomly picked from each cultivar across all three tents) were collected between 10:00 am and 04:00 pm using 1-5 $\mu \mathrm{L}$ microcapillary tubes (Hirschmann Laborgeräte, ringcaps ${ }^{\circledR}$, Eberstadt, Germany). The tubes were weighed on a precision scale before and after sampling, and the difference revealed the nectar quantity of the investigated flowers.

\section{Flower scent analyses}

The flower scents of the Calibrachoa cultivars were collected by enclosing two flowers with an approximate weight of $0.5 \mathrm{~g}$ in headspace vials $(20 \mathrm{~mL})$; flowers were kept frozen until used for the analyses. The compounds from the flower scents were identified by using headspace solid-phase microextraction (HS-SPME) combined with a gas chromatography system equipped with a mass spectrometry detector (GC-MS). Each plant cultivar was sampled with three replications such that 60 flower samples were analyzed.

For HS-SPME, a carboxene/polydimethylsiloxane/divinylbenzene (CAR/PDMS/DVB) fiber $(30 / 50 \mu \mathrm{m}$ and $1 \mathrm{~cm}$ fiber length) (Supelco, Steinheim, Germany) was used. The samples were incubated for $0.5 \mathrm{~min}$ at $30^{\circ} \mathrm{C}$, followed by headspace extraction for $5 \mathrm{~min}$ at the same temperature. Afterwards, the analytes were directly desorbed in the split/ splitless inlet at $250^{\circ} \mathrm{C}$ using a GC-MS SPME liner for $1 \mathrm{~min}$. After desorption, the fiber was cleaned under the conditions recommended by the manufacturer.

The GC-MS analyses were performed with a 7890B GC and 5977B MS (both Agilent Technologies, Waldbronn, Germany), an autosampler MPS robot and an olfactometry detection port ODP 3 (both Gerstel, Mülheim an der Ruhr, Germany). A polar Agilent J\&W DB-WAXms column (30 m length $\times 0.25 \mathrm{~mm}$ inner diameter $\times 0.25 \mu \mathrm{m}$ film thickness) (Agilent Technologies, Waldbronn, Germany) was used for separation of the flower scent compounds. Helium (5.0, Westfalen AG, Weißenhorn, Germany) was used as a carrier gas at a constant flow rate of $1.62 \mathrm{~mL} / \mathrm{min}$. The $\mathrm{GC}$ oven temperature was held at $40{ }^{\circ} \mathrm{C}$ for $3 \mathrm{~min}$ and then ramped at $5{ }^{\circ} \mathrm{C} / \mathrm{min}$ to $240{ }^{\circ} \mathrm{C}$. The $240{ }^{\circ} \mathrm{C}$ step was held for $10 \mathrm{~min}$. The following MS parameters were applied: MS mode, scan; scan range, $m / z$ 40-330; electron ionization energy, $70 \mathrm{eV}$; source temperature $230{ }^{\circ} \mathrm{C}$; and quadrupole temperature $150{ }^{\circ} \mathrm{C}$.

The data were analyzed using Agilent Mass Hunter B07.06 Gerstel Maestro (Gerstel, Mülheim an der Ruhr, Germany). The compounds of the flower scents were identified by their retention indices and a comparison of the mass spectra to those of authentic standards and data published in the literature, i.e., pherobase.com, webbook.nist.com and pubchem.ncbi.nlm.nih.gov. 


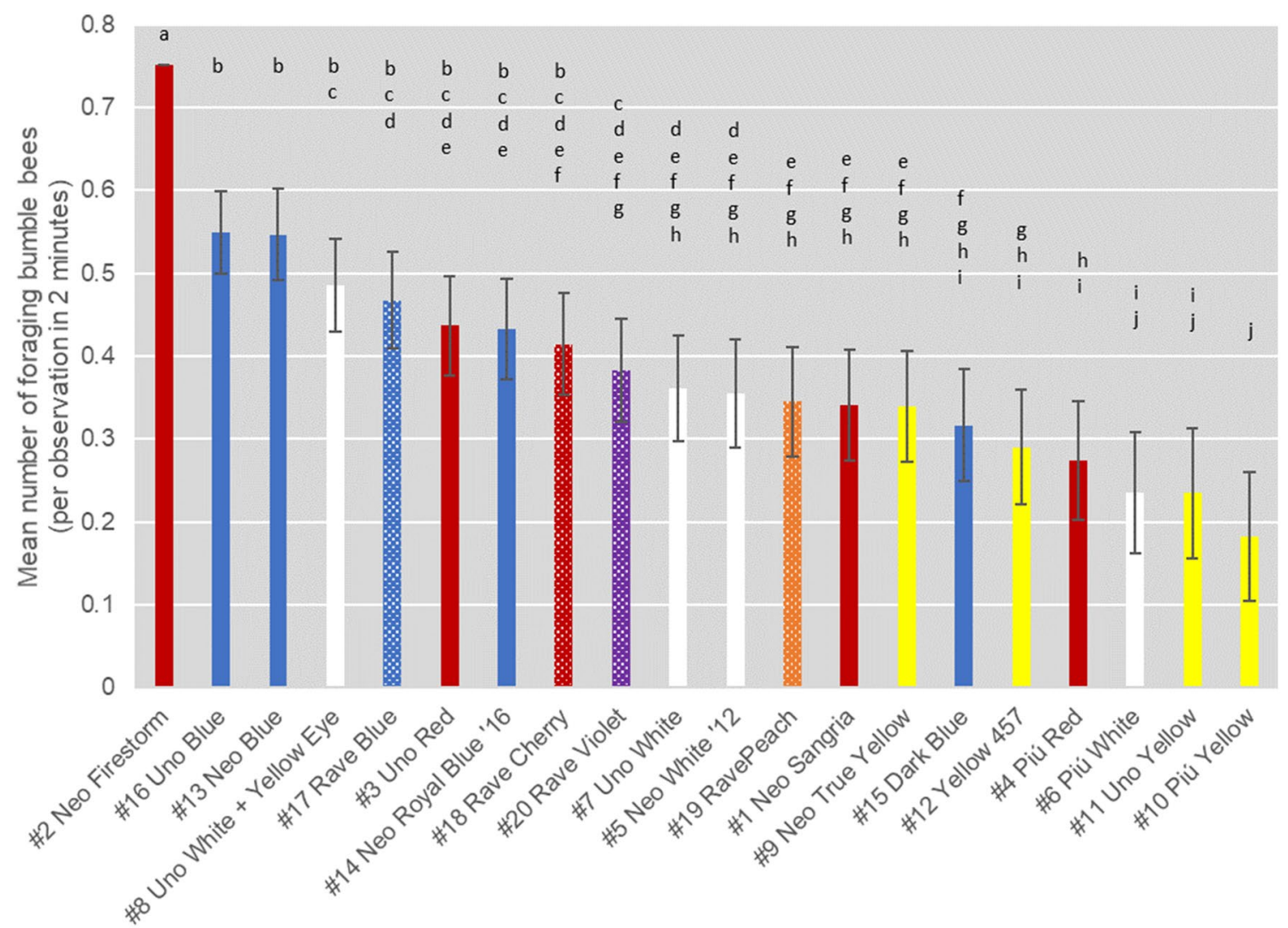

Fig. 1 Average number of foraging bumble bees (B. terrestris) and the standard deviation per Calibrachoa cultivar, which were controlled for any environmental and methodological impacts. The colors of the bars indicate the petal color of the respective cultivar. The let-

\section{Statistical analyses}

To make a scientifically objective statement regarding the attractiveness of the 20 tested Calibrachoa cultivars to bumble bees based on the flight tent observations, the number of bumble bee visits was controlled for any methodological and environmental impacts. Therefore, the data were analyzed using an ANOVA-type generalized linear model (GLM) based on the restricted maximum likelihood (REML) method using R 3.6.2 (R Core Team 2019) and the package 'Ime4' (Bates et al. 2015). Based on the residual and Q-Q-plot, a Poisson distribution using the natural logtransformation was chosen for the GLM, which is quite typical for count data. The varietal effect was separated from the environmental effect of the year, repetition, repetition nested within the tent and location. For the least squares means test, the package 'emmeans' (Lenth 2020) was used. The obtained lsmeans values for the cultivar effect were then transformed back to the original scale. Tukey-adjusted $P$-values for the multiple pairwise comparisons among cultivars were calculated and visualized via a compact letter display. We proceeded similarly for the count data of the ters above the bars represent significant differences based on the least squares means test, where cultivars sharing the same letter are not significantly different from each other $(P>0.05)$

flower visitors in the open field observations. However, due to legibility reasons, we waived the graphical presentation of the letters in the figure.

Based on the spectral reflectance, the color locus of each cultivar was determined in the color hexagon according to Chittka (1992). Therefore, the statistical analyses of the spectral reflectance data and the graphical presentation on the color hexagon were performed in R 3.6.2 (R Core Team 2019) with the package 'pavo' (Maia et al. 2019). As we used the bumble bee $B$. terrestris as our model species in this study, the sensitivity maxima needed to be adjusted to fit its trichromatic system. The following values were taken as the maxima for the UV, blue and green receptors: $328 \mathrm{~nm}$, $428 \mathrm{~nm}$ and $536 \mathrm{~nm}$, respectively (Peitsch et al. 1992).

The GLM was further used to evaluate the importance of the bee-perceived petal color on the attractiveness to bumble bees. The varietal effect was completely replaced by the petal color effect to avoid confounding between the cultivar and color. Again, the least squares means test from the package 'emmeans' (Lenth 2020) was applied to the petal color effect data. We tested the effects of the series and the nectar quantities in a similar manner. 


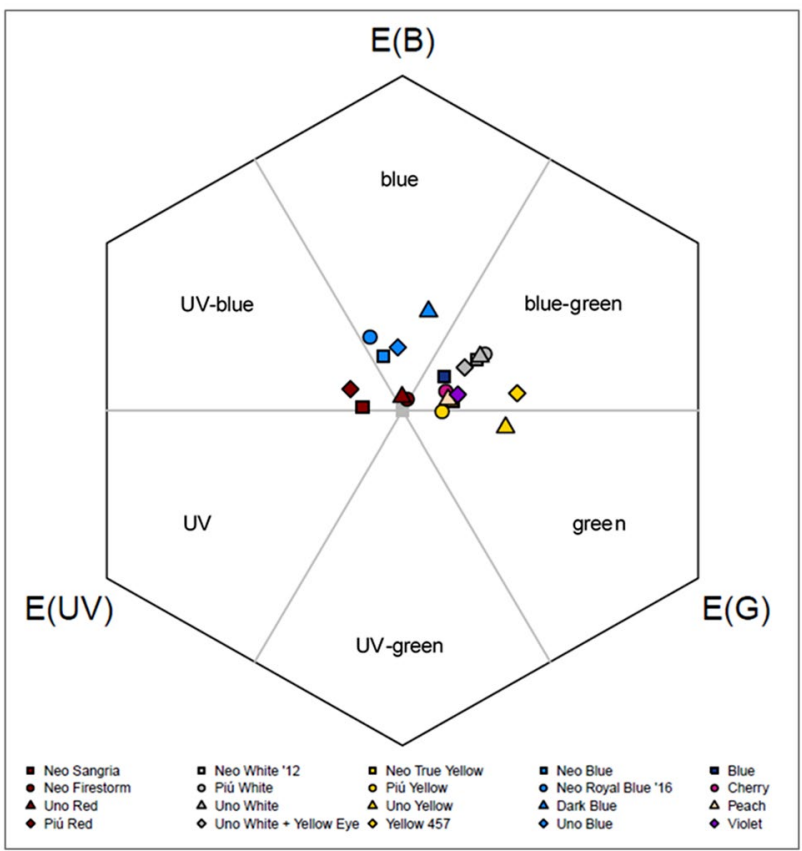

Fig. 2 The petal color loci of the 20 Calibrachoa cultivars compared in the color hexagon used by Chittka (1992), whereby ' $B$ ' blue, ' $U$ ' UV and ' $G$ ' green
The floral morphometric measurements (horizontal/vertical flower diameter, horizontal/vertical corolla diameter, corolla depth and stamen lengths) were correlated with the count data of the response variable (number of bumble bee visits) in R 3.6.2 (R Core Team 2019) using Spearman's rank-order correlation (Spearman 1906). The importance of the methodological and environmental impact factors on the expression of the floral morphometric parameters was analyzed with ANOVA using a slightly modified model: the year effect was dropped since the floral morphometric measures were only carried out in 2017.

Visualization of the nonmetric multidimensional scaling (NMDS) of the single flower scent components depending on the pollinator attractiveness was performed with $\mathrm{R}$ 3.6.2 (R Core Team 2019) and the 'vegan' package (Oksanen et al. 2019). The raw data were the quantitative concentrations of the flower scent substances (peak area in units). The data were square-root transformed prior to the analysis, and the Bray-Curtis similarity index was used to measure the similarities/dissimilarities of the data. The stress value indicates the level of reliability of the two-dimensional plot whereby a stress equal to or below 0.1 is considered a fair representation.

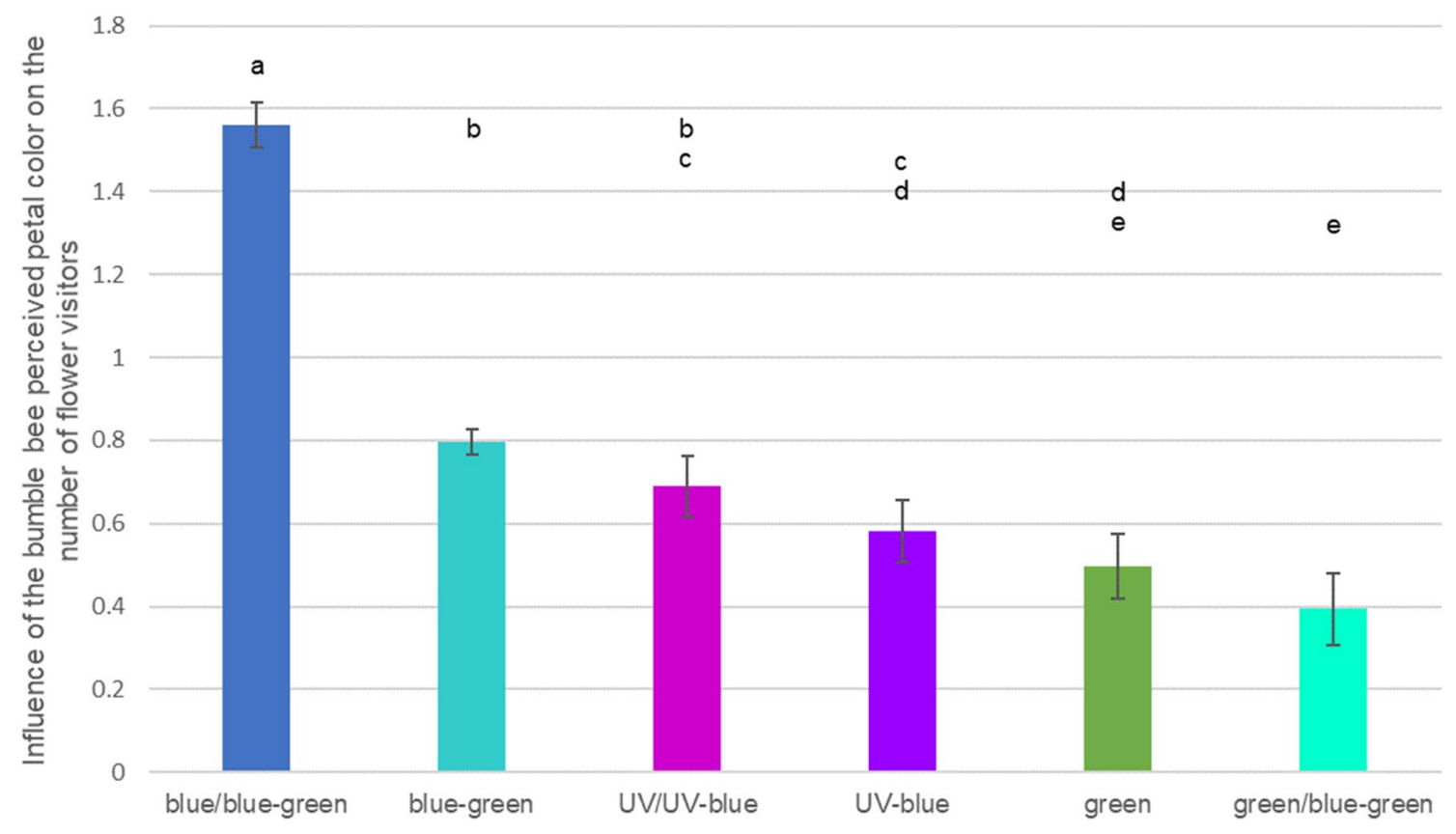

Bee color

Fig. 3 Influence of the bumble bee-perceived petal color of the tested Calibrachoa cultivars on the number of $B$. terrestris flower visitors and the standard deviation. The letters above the bars represent sig- nificant differences based on the least squares means test, where beeperceived colors sharing the same letter are not significantly different from each other $(P>0.05)$ 
Fig. 4 Influence of the Calibrachoa series of the tested cultivars on the number of $B$. terrestris flower visitors and the standard deviation. The letters above the bars represent significant differences based on the least squares means test, where the series sharing the same letter are not significantly different from each other $(P>0.05)$

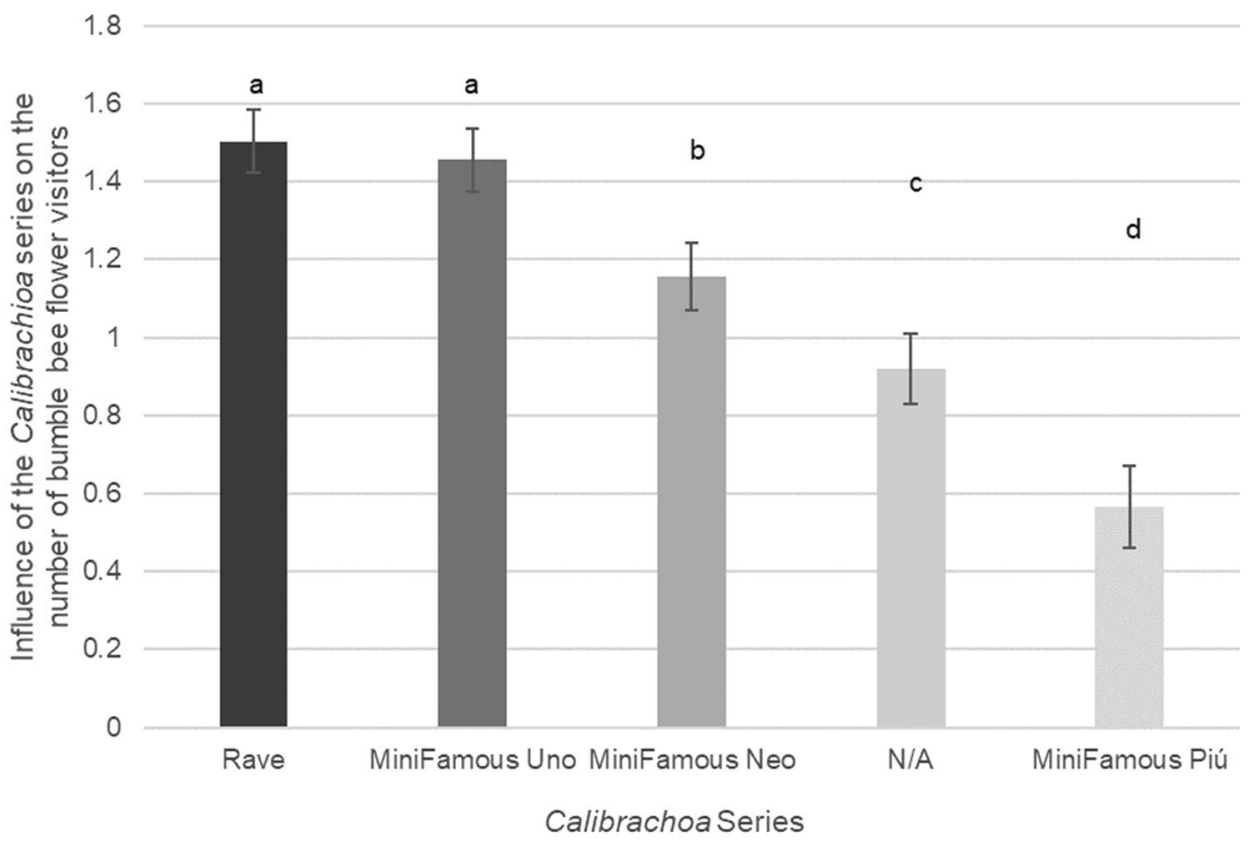

To investigate whether the petal color and floral aroma profiles interact, we used ANOSIM and SIMPER (PAST 4.03). Data were compared using one-way analysis of similarity (ANOSIM, similarity index $=$ Bray-Curtis, maximum permutations $=9,999$ ) to determine if differences in the floral scent occurred among cultivars with the same petal color (as viewed by bees). The floral scents were also quantified through one-way similarity percentages (SIMPER, similarity index $=$ Bray-Curtis) to identify similarities or dissimilarities among the same-colored cultivars.

\section{Results}

\section{Variation in bumble bee attractiveness among the Calibrachoa cultivars}

In total, 6,327 bumble bees were recorded foraging at the Calibrachoa plants across the two-year observation period in Heidelberg and Stuttgart. The number of B. terrestris visitors varied highly among the Calibrachoa cultivars. Of all tested cultivars, 'Neo Firestorm' was the most attractive cultivar, with 0.75 flower visitors on average in two minutes, followed by 'Uno Blue' and 'Neo Blue', with a mean of 0.55 flower visitors. The least attractive cultivar was 'Piú Yellow', with 0.18 flower visitors. Cultivar was a highly significant factor for attractiveness to the bumble bee $B$. terrestris (Wald test: $D f=19$, Wald Statistic $=662.61, P<0.001)$. The results of the least squares means test showed that the cultivar 'Neo Firestorm' was significantly different in the number of visitors compared with all other cultivars (Fig. 1).

\section{Differences in petal colors and impacts on bumble bee visitors}

The comparison of the petal color reflectance in the Calibrachoa cultivars showed that the color loci of the investigated cultivars formed a gradient across the UV-blue, blue and blue-green sections in the color hexagon (Fig. 2). Furthermore, it can be seen that the majority of the color loci in the five color sets clustered as follows: the color set 'blue' appeared in the section bee-blue, 'white' and 'rave' appeared in the section bee blue-green, 'yellow' appeared in the transition between bee blue-green and bee-green, and 'red' appeared in the transition between UV-blue, bee-blue and bee blue/blue-green. Within each color set, the color loci distances of some cultivars were extremely small $(<0.1)$, and some of the cultivars were closely located to the center of the color hexagon (distance less than 0.1 hexagon distance) (Supplementary Information Table S1).

Statistical analyses linking the bumble bee-perceived petal color with the attractiveness of the Calibrachoa cultivars showed that petal color had a significant impact on the number of $B$. terrestris visitors (Wald test: $D f=6$, Wald Statistic $=493.15, P<0.001)$. The cultivars appearing blue/ blue-green showed the most positive impact, followed by the blue-green, UV/UV-blue and UV-blue cultivars (Fig. 3). In contrast, the green color and the combination of green/ blue-green showed less influence on the number of flower visitors. The results of the pairwise comparisons indicated that the blue/blue-green color was significantly different from the others.

Further statistical analysis showed that in addition to beeperceived petal color, the series of investigated cultivars also 


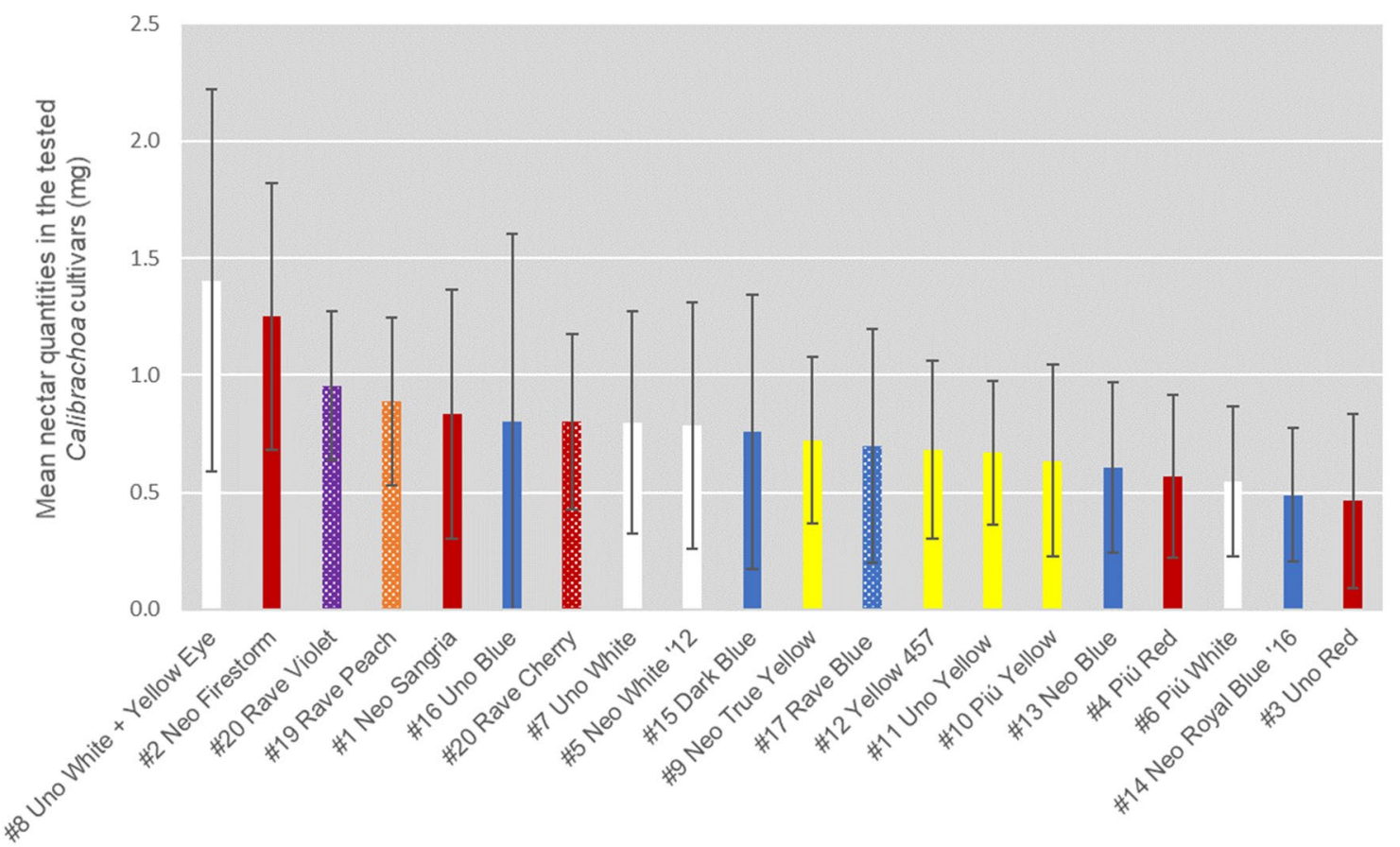

Fig. 5 Mean amount of nectar and standard deviations in the 20 investigated Calibrachoa cultivars. The colors of the bars indicate the petal color of the respective cultivar

Fig. 6 Nonmetric multidimensional scaling (NMDS) of the aroma profiles of the 20 tested Calibrachoa cultivars classified into four groups 'highly attractive' (green), 'moderately attractive' (yellow), 'slightly attractive' (orange) and 'very slightly attractive' (red). This graphic representation is based on the quantitative analysis of the 27 flower scent compounds. The spatial proximity of some individual compounds to the highly attractive class indicates that these compounds might be relevant for the attractiveness of the floral scent to B. terrestris

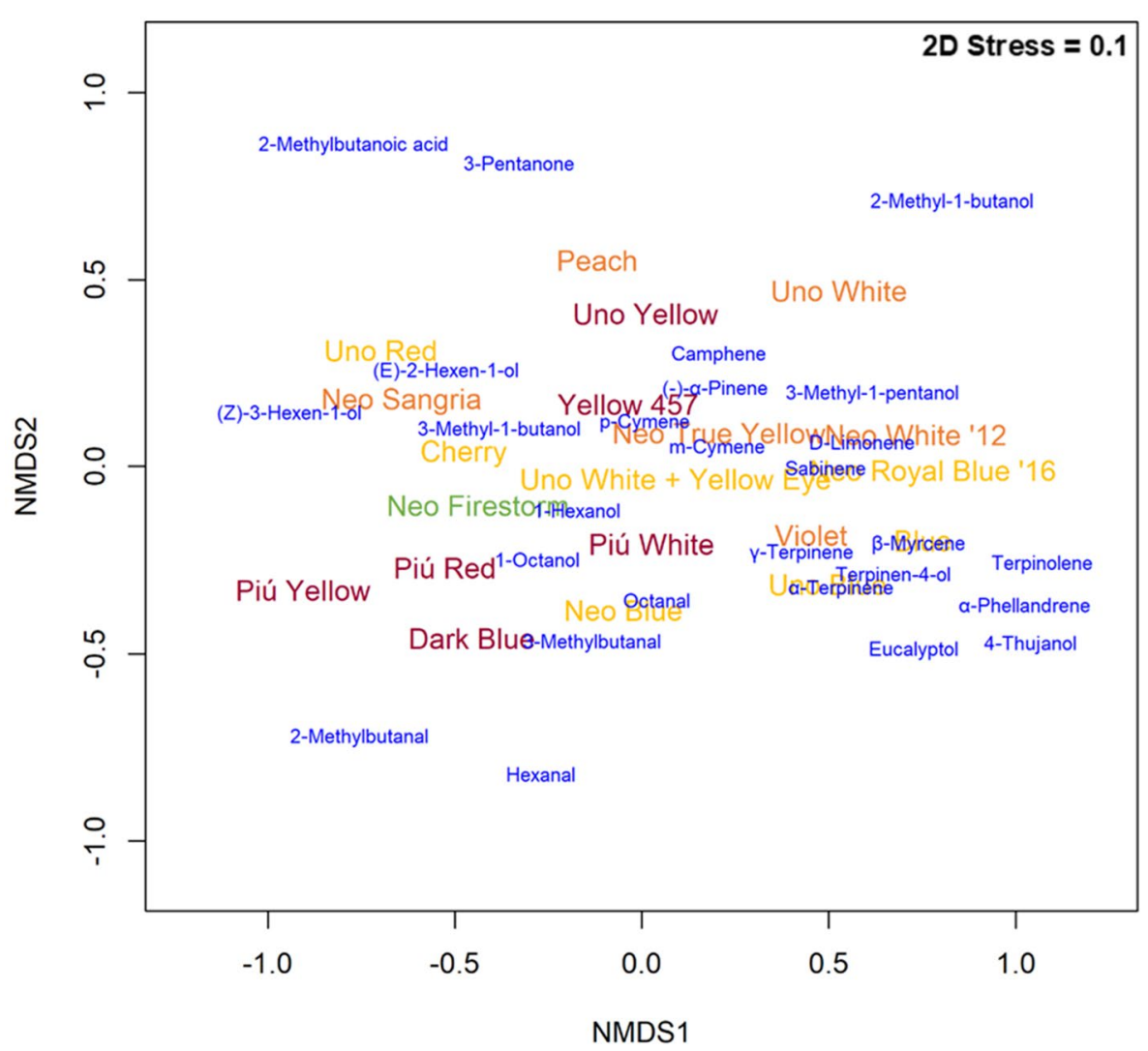


Fig. 7 Relative abundance of the different insect groups on the Calibrachoa cultivars in 2017 and 2019 in Stuttgart

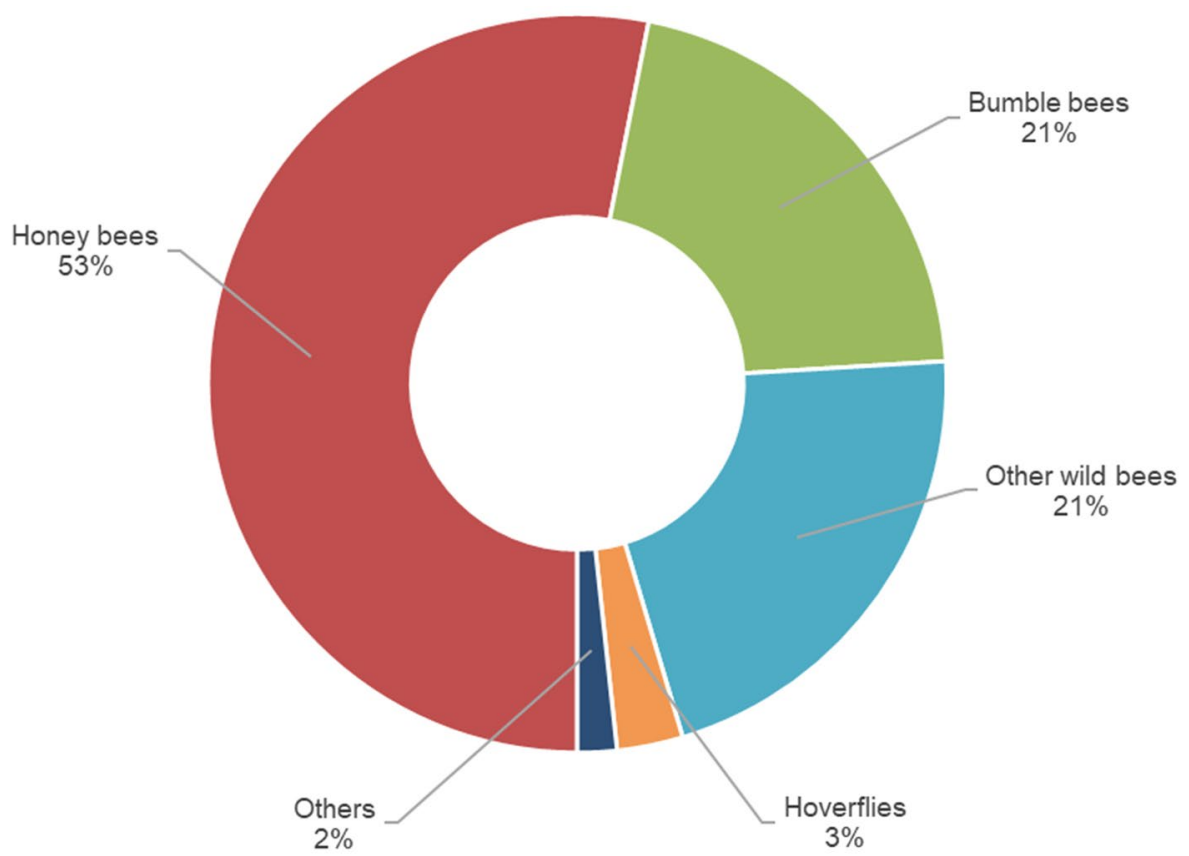

had a highly significant impact on bumble bee attractiveness (Wald test: $D f=5$, Wald Statistic $=292.50, P<0.001$ ). While the three series Rave ${ }$, MiniFamous $₫$ Uno and MiniFamous ${ }^{\circledR}$ Neo had a positive effect on the number of $B$. terrestris flower visitors, the series MiniFamous ${ }$ Piú and the cultivar without a denomination negatively influenced the number of bumble bee visitors (Fig. 4). The pairwise comparisons showed that all combinations, except for Rave ${ }$ and MiniFamous® Uno, were significantly different.

\section{Floral morphometric parameters in the Calibrachoa cultivars}

The mean floral morphometric parameters were highly variable among the 20 tested Calibrachoa cultivars (Supplementary Information Table S2). However, overall, the correlations of the floral morphometric parameters with the number of $B$. terrestris visitors were very low, with a correlation coefficient ranging only from 0.002 to 0.008 . In addition, we found that the expression of the floral morphometric parameters not only depended on the cultivar but also to a substantial degree on external factors such as the location or the tent number. Regarding flower diameter, corolla diameter and corolla depth, these external factors explained between $45.9 \%$ and $60.1 \%$ of flower expression. In contrast, the lengths of the five stamens were mainly dependent on the Calibrachoa cultivar itself. This cultivar dependency ranged from $66.3 \%$ to $73.5 \%$; finally, the external factors explained only $1 / 3$ of the variation in the length of the stamen.

The mean nectar quantities varied highly within the 20 investigated cultivars (Fig. 5). In the cultivar 'Uno
White + Yellow Eye', the highest amount of $1.41 \mathrm{mg}$ was recorded, followed by 'Neo Firestorm', with a mean amount of $1.25 \mathrm{mg}$. In 'Neo Royal Blue '16' and 'Uno Red', we detected the lowest amounts of nectar, at 0.49 and $0.46 \mathrm{mg}$, respectively. The statistical analyses indicated that the mean nectar amount was a highly significant impact factor on bumble bee attractiveness (Wald test: $D f=1$, Wald Statistic $=170.95, P<0.001)$. However, the standard deviations in the sampled flowers were high, suggesting a high spread of nectar amounts in the flower samples.

\section{Floral aroma profiles of the Calibrachoa cultivars and impact on bumble bee attractiveness}

We identified 27 compounds in the floral aroma profiles of the Calibrachoa cultivars that belong to seven different chemical groups: monoterpenes (12 components), alcohols (7), aldehydes (4), alkanols (1), carboxylic acids (1), ketones (1) and menthadiene (1). Concerning the different Calibrachoa cultivars, qualitative and quantitative differences were apparent. The only compound that occurred in all cultivars was 3-methyl-1-butanol. Two substances, $p$ - and $m$-cymene, occurred in 19 cultivars. The scarcest substance was 2-methylbutanoic acid, which was found only in the cultivar 'Uno Red'. The compounds were also present in varying concentrations in the tested cultivars. (-)- $\alpha$-Pinene, sabinene, $\beta$-myrcene, $\alpha$-terpinene, 3 -methyl-1-butanol, $\gamma$-terpinene, $m$ - and $p$-cymene and terpinen-4-ol were found at high concentrations in our samples. 2-Methylbutanal, 3-methylbutanal, 3-pentanone, camphene, hexanal, $\alpha$-phellandrene, D-limonene, 2-methyl-1-butanol, eucalyptol, terpinolene, 


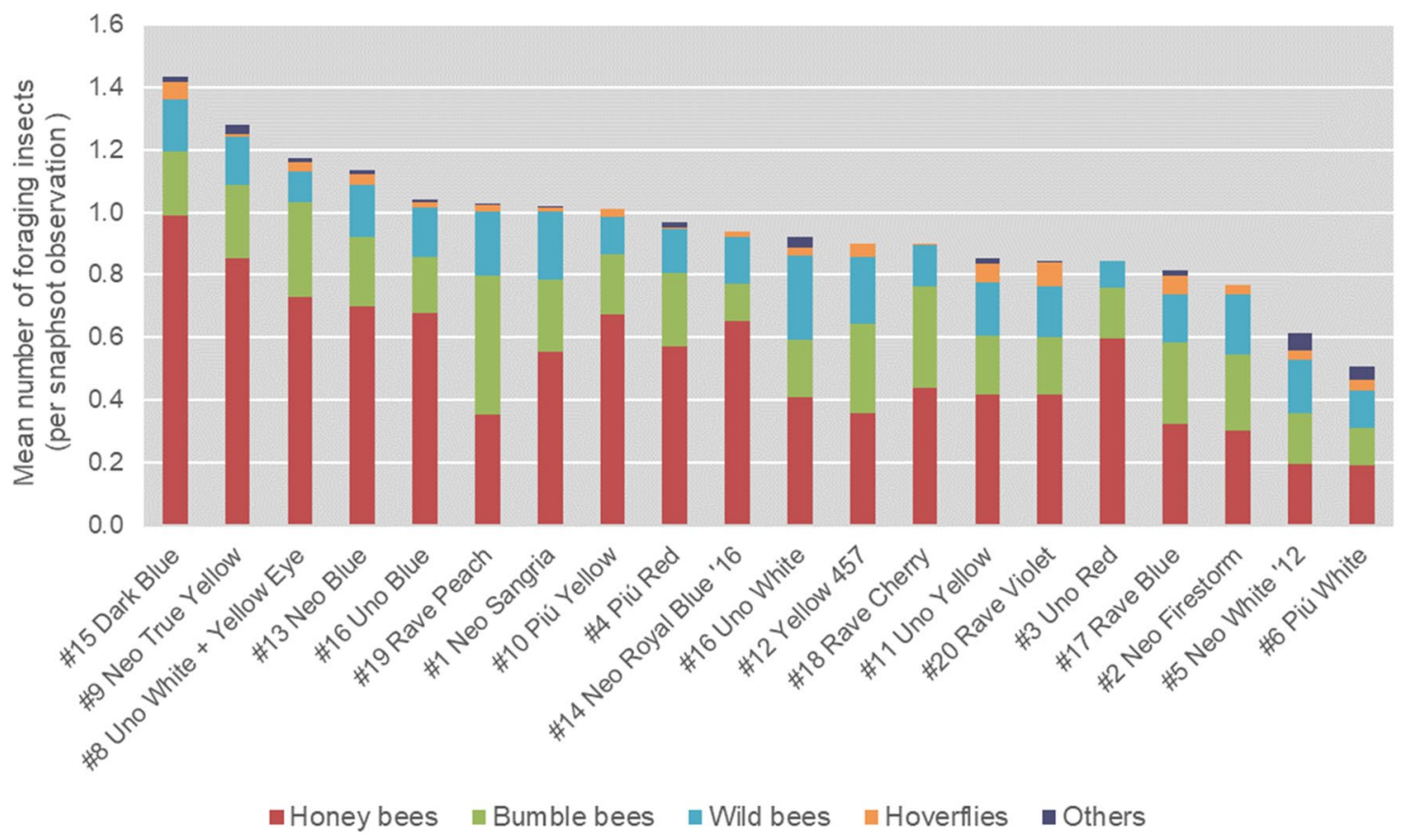

Fig. 8 Average number of foraging insects on the 20 different Calibrachoa cultivars. The mean values were controlled for any environmentals and methodological impacts

octanal, 3-methyl-1-pentanol, 1-hexanol, (Z)-3-hexen-1-ol, (E)-2-hexen-1-ol, 4-thujanol, 1-octanol and 2-methylbutanoic acid were detected in small concentrations or only in trace amounts (Supplementary Information Table S3).

NMDS based on the quantitative analysis of the aroma profiles of the 20 different Calibrachoa cultivars is displayed in Fig. 6. The figure shows that only a few individual substances in the floral aroma profile were directly associated with attractiveness to $B$. terrestris. Specifically, 7 compounds could be linked with highly or moderately attractive cultivars: 1-hexanol, octanal, $\alpha$-terpinene, 4-terpinen4-ol, $\beta$-myrcene, sabinene and (E)-2-hexen-1-ol. Typical compounds in Calibrachoa cultivars with very little attractiveness to bumble bees were camphene, (-)- $\alpha$-pinene and 3-methylbutanal. Some compounds could not be linked with either particularly high or low attractiveness: 2-methylbutanoic acid, 3-pentanone, 2-methyl-1-butanol, 2-methylbutanal and hexanal.

The ANOSIM analyses of the interaction between the bumble bee-perceived petal color and the floral scent of the cultivars showed that although we received an overall significant ratio of dissimilarities, it was only weakly positive $(R=0.1034, P<0.05)$. In addition, only two significant ratios could be found in the pairwise comparisons, namely, the pairs green/blue-green and blue $(R=0.39, P<0.05)$ and green/blue-green and blue-green $(R=0.57, P<0.05)$ (Supplementary Information Tables S4, S5). In SIMPER, the overall dissimilarity of the floral scent depending on the cultivar, which was grouped based on petal color, amounted to $68.9 \%$. The four substances (-)- $\alpha$-pinene, sabinene, $p$-cymene and 3-methyl-1-butanol contributed almost $70 \%$ of this dissimilarity (data available upon request).

\section{Other foraging insects on the Calibrachoa cultivars}

A total of 4,188 insects foraging on Calibrachoa were counted in the two years of field observation in Stuttgart. The majority of the flower visitors were honey bees at $53 \%$ (2,224 counted individuals). The bumble bees and other wild bees were equally abundant at $21 \%$ (877 and 894 counted individuals, respectively). Hoverflies (3\%, 121 individuals) and other pollinating insects ( $2 \%, 72$ individuals) were rarely observed (Fig. 7).

Within the tested Calibrachoa cultivars, the average number of insect visitors to the flowers varied greatly (Fig. 8). In sum, the cultivar 'Dark Blue' was visited most frequently, with an average of 1.4 flower visitors per snapshot observation. The least visited cultivar was 'Piú White', with only 0.5 foraging insect visitors. The observed insect groups also showed differences in their preference regarding the cultivars. 'Dark Blue' was favored by honey bees, and 'Rave Peach' was favored by bumble bees. The other wild bees preferred 'Uno White', while hoverflies were mainly observed on 'Rave Violet' and the other insects on 'Neo White '12'. The statistical analyses showed that the Calibrachoa cultivar had a highly significant impact on the number of insect 
visitors across all groups (Wald test: $D f=19$, Wald Statistic $=282.41, P<0.001)$.

\section{Hand-netted bumble bees and other wild bee species on Calibrachoa cultivars}

During the three catching periods in Stuttgart, 182 foraging bees were captured with a hand net (Supplementary Information Fig. S2). The most frequent genus was Lasioglossum (95 individuals), followed by Bombus (57 individuals) and Halictus (28 individuals). Only one individual each was captured from the two genera Anthidium and Andrena. In total, 12 different wild bee species were captured, with Lasioglossum morio being the most frequent, with $28 \%$. Except for Lasioglossum glabriusculum, which is currently classified as vulnerable in Germany (IUCN Red List, vulnerable), none of the caught wild bee species are currently listed on the IUCN Red List.

\section{Discussion}

\section{Calibrachoa as a foraging resource for flower-visiting insects}

In this multiyear study with more than 10,000 counted plant-insect interactions in tent and open field observations, we demonstrated that Calibrachoa constituted a suitable foraging resource for a high number of flower-visiting insects and that the occurrence of Calibrachoa increased the overall local food availability. During the observation intervals, we observed flower-visiting insects collecting both pollen and nectar, concluding that Calibrachoa served as an appropriate resource for both floral rewards. A previous study from our workgroup using detailed observation and melissopalynological methods confirmed that bees foraging on Calibrachoa indeed collected Calibrachoa pollen and nectar (Kretschmer 2017).

However, not all 20 Calibrachoa cultivars tested in this study seemed to be equally suitable, as some cultivars were visited considerably more often for foraging than others. This finding is in line with a comprehensive study performed by Garbuzov and Ratnieks (2015), where several hundred different aster cultivars were tested in regard to their flower visitor attractiveness. Their results clearly showed that the insect attractiveness to the main flower visitors - honey bees and hoverflies - varied greatly within the tested cultivars (Garbuzov and Ratnieks 2015). Such cultivar-related differences in the attractiveness of ornamental plants to insect visitors have also been described in previous studies on other ornamental plants, e.g., Zinnia (Yeargan and Colvin 2009; Erickson et al. 2020), Lavandula (Garbuzov and Ratnieks 2014b), Dahlia (Garbuzov et al. 2015), Lantana, Lobularia,
Pentas, and Tagetes (Erickson et al. 2020). As a result, these studies (including the present study) impressively show how important it is to continuously test new breeds and already established ornamental plant cultivars to provide information on their insect friendliness. This information might then be communicated with plant breeding companies as well as end consumers. Thus, the promotion of insect-friendly ornamental cultivars and the subsequent preferred use of these cultivars in urban plantings can be accomplished. This strategy is urgently needed to increase the urban nutritional resources for flower-visiting insects and to support the successful conservation of local insect diversity.

\section{Preferences of the bumble bee Bombus terrestris to Calibrachoa cultivars}

The large earth bumble bee $B$. terrestris was attracted to the 20 different Calibrachoa cultivars observed in this study to different degrees, and the mean number of $B$. terrestris visitors was found to vary up to fourfold. This large difference in bumble bee visitor attractiveness among the Calibrachoa cultivars raises the question of what floral trait might be responsible for this variation. Interestingly, we found that the cultivar 'Neo Firestorm', which is characterized by its bright red petal color, was clearly preferred over the other cultivars. However, to date, only one study in ornamental plants has investigated some flower traits that are known to attract flower-visiting insects (Garbuzov and Ratnieks 2015). By using the British national collection of asters, scientists tried to correlate some floral traits with the number of counted flower visitors in 228 different aster cultivars, and in conclusion, only bloom intensity could be directly linked with attractiveness to honey bees and hoverflies. Additional floral parameters, such as flower color, disc floret area and total capitulum, did not significantly influence the attractiveness to flower visitors. In contrast, we clearly demonstrated in our study that petal color represented an important factor in the attractiveness of Calibrachoa cultivars to B. terrestris. Cultivars that appeared blueish-green or UV-blue to the bumble bees were considerably visited more often for foraging than cultivars that appeared solely green or with a high proportion of green. This finding is in line with some previous studies that also showed that UV and blue colors are particularly interesting for bumble bees in artificial and natural flowers (Gumbert 2000; Reverté 2016). However, the high preference of bumble bees for the red-flowered cultivars is rather uncommon. For a long time, the color red was assumed not to be perceived by bees due to the lack of a corresponding receptor (Peitsch et al. 1992); therefore, a possible reason for this lack of perception was considered to be the exclusion of bees from the relevant pollination systems (Raven 1972; Rodríguez-Gironés and Santamaría 2004). Previous studies contrastingly showed that despite 
their rarity, some red flowers might indeed be pollinated by bees (Chittka and Waser 1997; Martínez-Harms et al. 2010; Chen et al. 2020). This could be the result of an improved perception of the flowers, which is achieved either by a sufficient reflection of UV or UV-blue light or a sufficient achromatic contrast of the red flowers (Martínez-Harms et al. 2010; Chen et al. 2020). Both aspects might apply in our case to red-flowered Calibrachoa cultivars. However, due to contradictory results, conclusive evidence regarding the importance of petal colors in ornamental plants for flower visitors is still lacking. However, it has been suggested that in some genera and species, color can be used as a predictor for insect visitation, and it has been shown that petal color is indeed important for flower-visiting insects, e.g., in Zinnia ssp. and Lobularia maritima. However, this could not be verified in Symphyotrichum spp. (asters) and Lantana camara (Garbuzov and Ratnieks 2015; Erickson et al. 2020).

In addition to visual floral signals, many bee species additionally rely on olfactory signals, either in combination or as a single signal (Burger et al. 2010; Schäffler et al. 2015). In this study, in total, we identified 27 single floral scent compounds, with the majority of them belonging to the chemical groups of monoterpenes and alcohols. Both chemical groups are known to contain substances that occur as secondary metabolites in flowering plants and can have attractive functions in pollinators (Levin et al. 2001; Wink 2016; Cordeiro et al. 2016). Among the 20 Calibrachoa cultivars, we found the floral aroma profiles to be highly varying but without a discernible pattern, e.g., dependent on petal color. The statistical analyses on the interaction between the floral scent and petal color also indicated only a weak positive correlation. A further attempt to correlate the single floral scent compounds to attractiveness to bumble bees revealed that only 7 compounds contributed to cultivar attractiveness, while the remaining 20 compounds had little or no impact. As we obtained these results by statistical evaluations only, we highly recommend verifying these results in further laboratory bioassays to separately test the effects of olfactory and visual signals of Calibrachoa flowers on B. terrestris (see Burger et al. 2010; 2017).

It is very likely that in addition to the already described floral signals, other floral characteristics might have contributed to the varying attractiveness of the Calibrachoa cultivars. Previously published literature demonstrated that the quality and quantity of pollen and nectar can drive floral choices in pollinators (Krömer et al. 2008; Di Pasquale et al. 2013; Somme et al. 2015). To a certain extent, this might also apply to Calibrachoa cultivars. Although we found the nectar quantity in the Calibrachoa flower samples to be highly variable, we obtained the first indications that the nectar quantity indeed impacted attractiveness. Therefore, whether nectar and pollen analyses can be performed and correlated with bee attractiveness in ornamental plants should be considered in more detail in further studies.

Based on these findings, we suggest classifying the tested Calibrachoa cultivars as 'attractive' ( $>0.5$ B. terrestris visitors) and 'less attractive' $(<0.5 \mathrm{~B}$. terrestris visitors) cultivars according to their number of $B$. terrestris visitors. Thus, the three most attractive cultivars, 'Neo Firestorm', 'Uno Blue' and 'Neo Blue', might be recommended for urban plantings. As the remaining cultivars have proven to be a less suitable foraging resource for $B$. terrestris, we suggest using these cultivars in combination with other bumble beefriendly plants, e.g., Dahlia x hortensis, Lavandula angustifolia, Nepeta racemose, Stachys officinalis and Scabiosa columbaria (Rollings and Goulson 2019; Marquardt et al. 2020).

\section{Preferences of other flower-visiting insects}

Previous studies have demonstrated that different insect groups show group-specific preferences for ornamental plant species and even cultivars (Garbuzov and Ratnieks 2014b; Erickson et al. 2020). Our comprehensive results on the preference of B. terrestris for Calibrachoa cultivars might therefore not be representative of other flower visitors, and our study should be repeated with other insect groups.

In the open field observations, we recorded high numbers of flower visitors collecting pollen and nectar on all 20 offered cultivars, indicating that Calibrachoa is very likely also contributing to the nutrition of a large spectrum of foraging insects. Bees represented the group with the largest number of individuals. Among this group, more than half of the observed individuals belonged to honey bees, which are considered 'supergeneralists' and are known to forage from a large range of native and nonnative flowering plants (Memmott and Waser 2002; Potts et al. 2010). The other half consisted of both bumble bees and other wild bees in equal shares. Our data indicate that bumble bees and generalist species of wild bees exclusively foraged on the offered Calibrachoa cultivars. This can be explained by the lack of Calibrachoa-associated bee species in Germany, which is consistent with other studies where mainly generalist bee species were found foraging on nonnative ornamental plants (Memmott and Waser 2002; Frankie et al. 2005; Geslin et al. 2013; Lowenstein et al. 2019; Erickson et al. 2020).

With this study, we highlighted that the use of the ornamental plant Calibrachoa increased the overall food availability for flower-visiting insects, at least for generalist bee species. Furthermore, due to the extended blooming period and the high abundance of flowers per plant, Calibrachoa has the potential to lengthen the flowering season and to provide a reliable and continuous foraging resource during periods of food shortage. For these reasons, Calibrachoa 
can certainly be advantageous for urban insect communities. However, the present study also illustrated large differences in the attractiveness of the tested Calibrachoa cultivars to different flower-visiting insect groups. To support a great diversity of insects, it is recommended to use I) cultivars that can be labeled "insect-friendly" through standardized tests and II) various cultivars that cover the specific preferences of different flower-visiting insect groups.

\section{Methodological approaches}

The floral aroma profile of Calibrachoa was analyzed for the first time in this study by using headspace solid-phase microextraction (HS-SPME) coupled with gas chromatography (GC-MS). We relied on this method because it has been proven to be suitable for aroma profile analyses and the identification of a broad range of floral odorants in plants (Bicchi et al. 2007; Rigling et al. 2019). Due to organizational reasons, however, we were obliged to freeze the flower samples prior to the floral scent analyses. Whether and how this might have affected the aroma profiles of our samples is currently a matter of speculation, as data regarding the effects of the freezing process on floral scent are still inconclusive (see Salvador et al. 2017; Culleré et al. 2013; but Xiao et al. 2015). Additionally, to date, no data of (unfrozen) Calibrachoa floral scents have been published, so a comparison of results is not possible. However, studies suggest that freezing is one of the most suitable preservation methods, and the observed decrease in volatile compounds in comparison with freshly analyzed material is still within an acceptable level (Salvador et al. 2017).

Interestingly, we found the expression of some floral morphometrics to be particularly dependent on the environmental context. This dependency, however, varied greatly within the examined floral morphometric parameters. While the lengths of the stamens were mainly cultivar-specific and less dependent on the environment, the expression of flower diameter, corolla diameter and corolla depth was highly dependent on the environmental context, such as the location and flight tent number. The strong impact of environmental factors on these morphometric characteristics is most likely the reason why we could not find a correlation of these characteristics with the attractiveness to insects.

The amount of nectar within a flower might also contribute to their attractiveness. Here, we found the nectar quantities of the flower samples to be highly variable, which might be traced back to the fact that we picked the flower samples randomly and independent of their age. However, unpublished observations indicate that nectar production in Calibrachoa depends not only on environmental factors such as daytime and weather conditions but also on the age of the flower (Dominik Losert, personal communication). To obtain reliable results, we suggest a standardized method to record nectar quantities in Calibrachoa cultivars, in which the age of the flower is recorded and considered in the evaluations.

The identification of distinct floral traits in Calibrachoa could be useful for breeding practices to increase insect friendliness in Calibrachoa cultivars. Unfortunately, this intention has become very challenging for two reasons. First, the expression of some floral morphometric characteristics depended on environmental factors. This makes selective breeding of insect-friendly cultivars on the basis of these characteristics almost impossible. Second, the investigation of the aroma profiles in Calibrachoa cultivars revealed only a few single compounds that may be related to insect friendliness. However, in contrast to the floral morphometric traits and the floral aroma profile, we obtained clear indications that the red and blue petal colors in the Calibrachoa cultivars promoted higher attractiveness to the model species $B$. terrestris. This information can be utilized and should be further pursued to generate Calibrachoa cultivars that are more attractive for flower-visiting insects.

Supplementary Information The online version contains supplementary material available at https://doi.org/10.1007/s11829-021-09844-2.

Acknowledgements We thank Wolfgang Henle, Michael Kurz and the whole team from the State School for Horticulture and Agriculture (SfG) in Stuttgart-Hohenheim for providing us free space to install the testing areas, including the three flight tents, on their premises. Special thanks go to Mathias Zäpfel and his trainees (State Horticultural College and Research Institute (LVG) Heidelberg) for the setup of the testing plants at both locations in Heidelberg and Stuttgart-Hohenheim in all three study years. Acquiring all the data would not have been possible without the help of Susanne Bonk (LVG), Marietheres Klinger (LVG) and Leni Stahl (SfG), so thank you for your support. MM owes particular thanks to Prof. Dr. Manfred Ayasse, Dr. Hannah Burger, Dr. Omer Nevo and the whole team from the Chemical Ecology workgroup at the Institute of Evolutionary Ecology and Conservation Genomics at Ulm University for permission to use the Jaz spectrometer and for their support while performing the spectral reflectance measurements. Finally, we are grateful for the helpful comments and suggestions from two anonymous reviewers who helped to improve the earlier version of the manuscript.

Author contributions DL, UR and PR conceived the research; MM, LAK and NW collected the data; LK, MM, KS and MR analyzed the data; and MM, LK and PR wrote the paper.

Funding Open Access funding enabled and organized by Projekt DEAL. The project was funded by the European Agricultural Fund for Rural Development: Europe investing in rural areas with the participation of the State of Baden-Württemberg.

\section{Declarations}

Conflict of interest The authors declare that they have no conflicts of interest. 
Open Access This article is licensed under a Creative Commons Attribution 4.0 International License, which permits use, sharing, adaptation, distribution and reproduction in any medium or format, as long as you give appropriate credit to the original author(s) and the source, provide a link to the Creative Commons licence, and indicate if changes were made. The images or other third party material in this article are included in the article's Creative Commons licence, unless indicated otherwise in a credit line to the material. If material is not included in the article's Creative Commons licence and your intended use is not permitted by statutory regulation or exceeds the permitted use, you will need to obtain permission directly from the copyright holder. To view a copy of this licence, visit http://creativecommons.org/licenses/by/4.0/.

\section{References}

Baldock KCR, Goddard MA, Hicks DM, Kunin WE, Mitschunas N, Morse H, Osgathorpe LM, Potts SG, Robertson KM, Scott AV, Staniczenko PPA, Stone GN, Vaughan IP, Memmott J (2019) A systems approach reveals urban pollinator hotspots and conservation opportunities. Nat Ecol Evol 3:363-373. https://doi.org/ 10.1038/s41559-018-0769-y

Banaszak-Cibicka W, Twerd L, Fliszkiewicz M, Giejdasz K, Langowska A (2018) City parks vs. natural areas-is it possible to preserve a natural level of bee richness and abundance in a city park? Urban Ecosyst 21:599-613. https://doi.org/10.1007/ s11252-018-0756-8

Bates AJ, Sadler JP, Fairbrass AJ, Falk SJ, Hale JD, Matthews TJ (2011) Changing bee and hoverfly pollinator assemblages along an urban-rural gradient. PLoS ONE 6(8):e23459. https://doi. org/10.1371/journal.pone.0023459

Bates D, Maechler M, Bolker B, Walker S (2015) Fitting linear mixed-effects models using lme4. J Stat Softw 67(1):1-48. https://doi.org/10.18637/jss.v067.i01

Bicchi C, Cordero C, Liberto C, Sgorbini B, Rubiolo P (2007) Reliability of fibres in solid-phase microextraction for routine analysis of the headspace of aromatic and medicinal plants. J Chromatogr A 1152(1-2):138-149. https://doi.org/10.1016/j. chroma.2007.02.011

Burger H, Dötterl S, Ayasse M (2010) Host-plant finding and recognition by visual and olfactory floral cues in an oligolectic bee. Funct Ecol 24(6):1234-1240. https://doi.org/10.1111/j.13652435.2010.01744.x

Burger H, Jürgens A, Ayasse M, Johnson SD (2017) Floral signals and filters in a wasp- and a bee-pollinated Gomphocarpus species (Apocynaceae: Asclepiadeae). Flora 232:83-91. https://doi. org/10.1016/j.flora.2017.05.009

Chen Z, Liu C-Q, Sun H, Niu Y (2020) The ultraviolet colour component enhances the attractiveness of red flowers of a bee-pollinated plant. J Plant Ecol 13(3):354-360. https://doi.org/10. 1093/jpe/rtaa023

Chittka L (1992) The colour hexagon: a chromaticity diagram based on photoreceptor excitations as a generalized representation of colour opponency. J Comp Physiol A 170:533-543. https://doi. org/10.1007/BF00199331

Chittka L, Raine NE (2006) Recognition of flowers by pollinators. Curr Opin Plant Biol 9(4):428-435. https://doi.org/10.1016/j. pbi.2006.05.002

Chittka L, Waser NM (1997) Why red flowers are not invisible to bees. Israel J Plant Sci 45(2-3):169-183. https://doi.org/10. 1080/07929978.1997.10676682

Comba L, Corbet SA, Barron A, Bird A, Collinge S, Miyazaki N, Powell M (1999) Garden flowers: insect visits and the floral reward of horticulturally-modified variants. Ann Bot 83(1):7386. https://doi.org/10.1006/anbo.1998.0798
Corbet SA, Bee J, Dasmahapatra K, Gale S, Gorringe E, La Ferla B, Moorhouse T, Trevail A, Van Bergen Y, Vorontsova M (2001) Native or exotic? Double or single? Evaluating plants for pollinator friendly gardens. Ann Bot 87(2):219-232. https://doi. org/10.1006/anbo.2000.1322

Cordeiro GD, Pinheiro M, Dötterl S, Alves-Dos-Santos I (2016) Pollination of Campomanesia phaea (Myrtaceae) by night-active bees: a new nocturnal pollination system mediated by floral scent. Plant Biol 19(2):132-139. https://doi.org/10.1111/plb. 12520

Culleré L, Ferreira V, Venturini ME, Marco P, Blanco D (2013) Chemi$\mathrm{cal}$ and sensory effects of the freezing process on the aroma profile of black truffles (Tuber melanosporum). Food Chem 136(2):518 525. https://doi.org/10.1016/j.foodchem.2012.08.030

De LC (2017) Improvement of ornamental plants-a review. Int J Horti 7(22):180-204

Di Pasquale G, Salignon M, Le Conte Y, Belzunces LP, Decourtye A, Kretzschmar A, Suchail S, Brunet J-L, Alaux C (2013) Influence of pollen nutrition on honey bee health: do pollen quality and diversity matter? PLoS ONE 8(8):e72016. https://doi.org/ 10.1371/journal.pone.0072016

Egerer M, Cecala JM, Cohen H (2020) Wild bee conservation within urban gardens and nurseries: effects of local and landscape management. Sustainability 12(1):293. https://doi.org/10.3390/ su12010293

Erickson E, Adam S, Russo L, Wojcik V, Patch HM, Grozinger CM (2020) More than meets the eye? The role of annual ornamental flowers in supporting pollinators. Environ Entomol 49(1):178188. https://doi.org/10.1093/ee/nvz133

Frankie GW, Thorp RW, Schindler M, Hernandez J, Ertter B, Rizzardi M (2005) Ecological patterns of bees and their host ornamental flowers in two northern California cities. J Kans Entomol Soc 78(3):227-246. https://doi.org/10.2317/0407.08.1

Fregonezi JN, de Freitas LB, Bonatto SL, Semir J, Stehmann JR (2012) Infrageneric classification of Calibrachoa (Solanaceae) based on morphological and molecular evidence. Taxon 61(1):120-130. https://doi.org/10.1002/tax.611009

Fregonezi JN, Turchetto C, Bonatto SL, Freitas LB (2013) Biogeographical history and diversification of Petunia and Calibrachoa (Solanaceae) in the Neotropical Pampas grassland. Bot J Linn Soc 171(1):140-153. https://doi.org/10.1111/j.1095-8339.2012. 01292.x

Garbuzov M, Ratnieks FLW (2014a) Listmania: the strengths and weaknesses of lists of garden plants to help pollinators. Bioscience 64(11):1019-1026. https://doi.org/10.1093/biosci/biu150

Garbuzov M, Ratnieks FLW (2014b) Quantifying variation among garden plants in attractiveness to bees and other flower-visiting insects. Funct Ecol 28(2):364-374. https://doi.org/10.1111/ 1365-2435.12178

Garbuzov M, Ratnieks FLW (2015) Using the British national collection of asters to compare the attractiveness of 228 varieties to flower-visiting insects. Environ Entomol 44(3):638-646. https:// doi.org/10.1093/ee/nvv037

Garbuzov M, Samuelson EEW, Ratnieks FLW (2015) Survey of insect visitation of ornamental flowers in Southover Grange Garden, Lewes UK. Insect Sci 22(5):700-705. https://doi.org/ 10.1111/1744-7917.12162

Geslin B, Gauzens B, Thébault E, Dajoz I (2013) Plant pollinator networks along a gradient of urbanisation. PLoS ONE 8(5):e63421. https://doi.org/10.1371/journal.pone.0063421

Gumbert A (2000) Color choices by bumble bees (Bombus terrestris): innate preferences and generalization after learning. Behav Ecol Sociobiol 48:36-43. https://doi.org/10.1007/s0026 50000213

Gunnarsson B, Federsel LM (2014) Bumblebees in the city: abundance, species richness and diversity in two urban 
habitats. J Insect Conserv 18:1185-1191. https://doi.org/10.1007/ s10841-014-9729-2

Hall DM, Camilo GR, Tonietto RK, Ollerton J, Ahrné K, Arduser M, Ascher JS, Baldock KCR, Fowler R, Frankie G, Goulson D, Gunnarsson B, Hanley ME, Jackson JI, Langellotto G, Lowenstein D, Minor ES, Philpott SM, Potts SG, Sirohi MH, Spevak EM, Stone GN, Threlfall CG (2017) The city as a refuge for insect pollinators. Conserv Biol 31(1):24-29. https://doi.org/10.1111/ cobi. 12840

Harder LD (1983) Flower handling efficiency of bumble bees: morphological aspects of probing time. Oecologia 57(1/2):274-280. http://www.jstor.org/stable/4216957

Harrison T, Winfree R (2015) Urban drivers of plant-pollinator interactions. Funct Ecol 29(7):879-888. https://doi.org/10.1111/13652435.12486

Hope D, Gries C, Zhu W, Fagan WF, Redman CL, Grimm NB, Nelson AL, Martin C, Kinzig A (2003) Socioeconomics drive urban plant diversity. Proc Natl Acad Sci 100(15):8788-8792. https://doi.org/ 10.1073/pnas. 1537557100

Hülsmann M, von Wehrden H, Klein AM, Leonhardt SD (2015) Plant diversity and composition compensate for negative effects of urbanization on foraging bumble bees. Apidologie 46:760-770. https://doi.org/10.1007/s13592-015-0366-x

Ishii HS (2006) Floral display size influences subsequent plant choice by bumble bees. Funct Ecol 20(2):233-238. https://doi.org/10. 1111/j.1365-2435.2006.01106.x

Jędrzejuk A, Meyer L, Serek M (2017) Characterization of interspecific hybrids of Petunia and Calibrachoa by multiplex PCR, DNA content, and chromosome number. J Hortic Sci Biotechnol 92(5):493-501. https://doi.org/10.1080/14620316.2017.1288554

Kishimoto S, Oda-Yamamizo C, Ohmiya A (2019) Comparison of petunia and calibrachoa in carotenoid pigmentation of corollas. Breed Sci 69(1):117-126. https://doi.org/10.1270/jsbbs. 18130

Knapp S, Dinsmore L, Fissore C, Hobbie SE, Jakobsdottir I, Kattge J, King JY, Klotz S, McFadden JP, Cavender-Bares J (2012) Phylogenetic and functional characteristics of household yard floras and their changes along an urbanization gradient. Ecology 93(8):8398. https://doi.org/10.1890/11-0392.1

Kretschmer L (2017) Attractiveness of ornamental flowers for pollinating insects in an urban area. Master's thesis, University of Hohenheim, Stuttgart

Krömer T, Kessler M, Lohaus G, Schmidt-Lebuhn AN (2008) Nectar sugar composition and concentration in relation to pollination syndromes in Bromeliaceae. Plant Biol 10(4):502-511. https:// doi.org/10.1111/j.1438-8677.2008.00058.x

Kulahci IG, Dornhaus A, Papaj DR (2008) Multimodal signals enhance decision making in foraging bumble-bees. Proc R Soc B 275(1636):797-802. https://doi.org/10.1098/rspb.2007.1176

Kunze J, Gumbert A (2001) The combined effect of color and odor on flower choices behavior of bumble bees in flower mimicry systems. Behav Ecol 12(4):447-456. https://doi.org/10.1093/ beheco/12.4.447

Lenth R (2020) Emmeans: estimated marginal means, aka least-squares means. R package version 1.4.8. https://CRAN.R-project.org/ package $=$ emmeans

Levin RA, Raguso RA, McDade LA (2001) Fragrance chemistry and pollinator affinities in Nyctaginaceae. Phytochemistry 58(3):429440. https://doi.org/10.1016/S0031-9422(01)00257-6

Liu G, Sun M, Zou P, Zhang W, Ni J (2020) The complete chloroplast genome sequence of a popular ornamental plant Calibrachoa hybrida (Solanaceae: Petunioideae). Mitochondrial DNA Part B 5(3):3374-3375. https://doi.org/10.1080/23802359.2020.1823257

Lowenstein DM, Matteson KC, Minor ES (2019) Evaluating the dependence of urban pollinators on ornamental, non-native, and 'weedy' floral resources. Urban Ecosyst 22:293-302. https://doi. org/10.1007/s11252-018-0817-z
Maia R, Gruson H, Endler JA, White TE (2019) pavo 2: new tools for the spectral and spatial analysis of colour in R. Methods Ecol Evol 10(7):1097-1107. https://doi.org/10.1111/2041-210X.13174

Marquardt M, Kienbaum L, Kretschmer LA, Penell A, Schweikert K, Ruttensperger U, Rosenkranz P (2020) Evaluation of the importance of ornamental plants for pollinators in urban and suburban areas in Stuttgart. Urban Ecosyst, Germany. https://doi.org/10. 1007/s11252-020-01085-0

Martínez-Harms J, Palacios AG, Márquez N, Estay P, Arroyo MTK, Mpodozis J (2010) Can red flowers be conspicuous to bees? Bombus dahlbomii and South American temperate forest flowers as a case in point. J Exp Biol 213:564-571. https://doi.org/10.1242/ jeb.037622

Matteson KC, Ascher JS, Langellotto GA (2008) Bee richness and abundance in New York City urban gardens. Ann Entomol Soc Am 101(1):140-150. https://doi.org/10.1603/0013-8746(2008) 101[140:BRAAIN]2.0.CO;2

McIntyre NE, Hostetler ME (2001) Effects of urban land use on pollinator (Hymenoptera: Apoidea) communities in a desert metropolis. Basic Appl Ecol 2(3):209-218. https://doi.org/10.1078/ 1439-1791-00051

McKinney ML (2006) Urbanization as a major cause of biotic homogenization. Biol Conserv 127(3):247-260. https://doi.org/10.1016/j. biocon.2005.09.005

Memmott J, Waser NM (2002) Integration of alien plants into a native flower - pollinator visitation web. Proc R Soc Lond B 269(1508):2395-2399. https://doi.org/10.1098/rspb.2002.2174

Murakami Y, Fukui Y, Watanabe H, Kokubun H, Toya Y, Ando T (2004) Floral coloration and pigmentation in Calibrachoa cultivars. J Hort Sci Biotechnol 79(1):47-53. https://doi.org/10.1080/ 14620316.2004.11511735

Oksanen J, Blanchet FG, Friendly M, Kindt R, Legendre P, McGlinn D, Minchin PR, O'Hara R B, Simpson GL, Solymos P, Stevens MHH, Szoecs E, Wagner H (2019) Vegan: community ecology package. R package version 2.5-6. https://CRAN.R-project.org/ package $=$ vegan

Olmstead RG, Bohs L, Migid HA, Santiago-Valentin E, Garcia VF, Collier SM (2008) A molecular phylogeny of the Solanaceae. Taxon 57(4):1159-1181. https://doi.org/10.1002/tax.574010

Peitsch D, Fietz A, Hertel H, de Souza J, Ventura DF, Menzel R (1992) The spectral input systems of hymenopteran insects and their receptor-based colour vision. J Comp Physiol A 170:23-40. https://doi.org/10.1007/BF00190398

Potts SG, Biesmeijer JC, Kremen C, Neumann P, Schweiger O, Kunin WE (2010) Global pollinator declines: trend, impacts and drivers. Trends Ecol Evol 25(6):345-353. https://doi.org/10.1016/j. tree.2010.01.007

R Core Team (2019) R: a language and environment for statistical computing. R Foundation for Statistical Computing, Vienna. https:// www.R-project.org/

Raguso RA (2004) Flowers as sensory billboards: progress towards an integrated understanding of floral advertisement. Curr Opin Plant Biol 7(4):434-440. https://doi.org/10.1016/j.pbi.2004.05.010

Raven PH (1972) Why are bird-visited flowers predominantly red? Evolution 26(4):674-674. https://doi.org/10.1111/j.1558-5646. 1972.tb01975.x

Reverté S, Retana J, Gómez JM, Bosch J (2016) Pollinators show flower colour preferences but flowers with similar colours do not attract similar pollinators. Ann Bot 118(2):249-257. https://doi. org/10.1093/aob/mcw103

Rigling M, Fraatz MA, Trögel S, Sun J, Zorn H, Zhang Y (2019) Aroma investigation of chios mastic gum (Pistacia lentiscus variety Chia) using headspace gas chromatography combined with olfactory detection and chiral analysis. J of Agric Food Chem 67(49):13420-13429. https://doi.org/10.1021/acs.jafc.9b00143 
Rode C, Winkelmann T, Meyer L, Debener T (2010) The ethylene 2 receptor gene as a robust molecular marker for intergeneric somatic hybrids between Petunia and Calibrachoa. Plant Breed 129(4):448-453. https://doi.org/10.1111/j.1439-0523.2009. 01699.x

Rodríguez-Gironés MA, Santamaría L (2004) Why are so many bird flowers red? PLoS Biol 2(19):e350. https://doi.org/10.1371/journ al.pbio. 0020350

Rollings R, Goulson G (2019) Quantifying the attractiveness of garden flowers for pollinators. J Insect Conserv 23:803-817. https://doi. org/10.1007/s 10841-019-00177-3

Rowe C, Guilford T (1999) Novelty effects in a multimodal warning signal. Anim Behav 57(2):341-346. https://doi.org/10.1006/anbe. 1998.0974

Salvador ÂC, Silvestre AJD, Rocha SM (2017) Unveiling elderflowers (Sambucus nigra L.) volatile terpenic and norisoprenoids profile: effects of different postharvest conditions. Food Chem 229:276285. https://doi.org/10.1016/j.foodchem.2017.02.037

Schäffler I, Steiner KE, Haid M, van Berkel SS, Gerlach G, Johnson SD, Wessjohann L, Dötterl S (2015) Diacetin, a reliable cue and private communication channel in a specialized pollination system. Sci Rep 5:12779. https://doi.org/10.1038/srep12779

Seto KC, Parnell S, Elmqvist T (2013) A global outlook on urbanization. In: Elmqvist T, Fragkias M, Goodness J, Güneralp B, Marcotullio PJ, McDonald RI, Parnell S, Schewenius M, Sendstad M, Seto KC, Wilkinson C (eds) Urbanization, biodiversity and ecosystem services: challenges and opportunities. Springer, Dordrecht

Somme L, Vanderplanck M, Michez D, Lombaerde I, Moerman R, Wathelet B, Wattiez R, Lognay G, Jacquemart A-L (2015) Pollen and nectar qualitiy drive the major and minor floral choices of bumble bees. Apidologie 46:92-106. https://doi.org/10.1007/ s13592-014-0307-0

Spearman C (1906) 'Footrule' for measuring correlation. Br J Psychol 2(1):89-108. https://doi.org/10.1111/j.2044-8295.1906.tb00174.x

Staab M, Pereira-Peixoto MH, Klein AM (2020) Exotic garden plants partly substitute for native plants as resources for pollinators when native plants become seasonally scarce. Oecologia 194:465-480. https://doi.org/10.1007/s00442-020-04785-8
Stehmann JR, Semir J (1997) A new species and new combinations in Calibrachoa (Solanaceae). Novon 7(4):417-419. https://doi.org/ 10.2307/3391775

Theodorou P, Radzevičiūtė R, Lentendu G, Kahnt B, Husemann M, Bleidorn C, Settele J, Schweiger O, Grosse I, Wubet T, Murray TE, Paxton RJ (2020) Urban areas as hotspots for bees and pollination but not a panacea for all insects. Nat Commun 11:576. https://doi.org/10.1038/s41467-020-14496-6

United Nations, Department of Economic and Social Affairs, Population Division (2014) World Urbanization Prospects: The 2014 revision. Highlights (ST/ESA/SER.A/352)

Ushimaru A, Kobayashi A, Dohzono I (2014) Does urbanization promote floral diversification? Implications from changes in herkogamy with pollinator availability in an urban-rural area. Am Nat 184(2):258-267. https://doi.org/10.1086/676855

Wenzel A, Grass I, Belavadi VV, Tscharntke T (2020) How urbanization is driving pollinator diversity and pollination-a systematic review. Biol Conserv 241:108321. https://doi.org/10.1016/j.biocon.2019.108321

Wijsman HJW (1990) On the inter-relationships of certain species of Petunia VI. New names for the species of Calibrachoa formerly included into Petunia (Solanaceae). Acta Bot Neerl 39(1):101-102

Winfree R, Aguilar R, Vázquez DP, LeBuhn G, Aizen MA (2009) A meta-analysis of bees' responses to anthropogenic disturbance. Ecology 90(8):2068-2076. https://doi.org/10.1890/08-1245.1

Wink M (2016) Evolution of secondary plant metabolism. eLS. John Wiley \& Sons, Ltd., Chichester. https://doi.org/10.1002/97804 70015902.a0001922.pub3

Xiao D-R, Liu R-S, He L, Li H-M, Tang Y-L, Liang X-H, Chen T, Tang Y-J (2015) Aroma improvement by repeated freeze-thaw treatment during Tuber melanosporum fermentation. Sci Rep 5:17120. https://doi.org/10.1038/srep17120

Yeargan KV, Colvin SM (2009) Butterfly feeding preferences for four Zinnia cultivars. J Environ Hortic 27(1):37-41. https://doi.org/10. 24266/0738-2898-27.1.37

Publisher's Note Springer Nature remains neutral with regard to jurisdictional claims in published maps and institutional affiliations. 